\title{
Controllable Assembly of Three Copper-Organic Frameworks: Structure Transformation and Gas Adsorption Properties
}

\author{
Xiuling Zhang ${ }^{1,2}$, Peng-fei Liu ${ }^{1}$, Na Wang ${ }^{1}$, Da-Shuai Zhang ${ }^{2} *$ \\ ${ }^{1}$ College of Chemical Engineering, Qingdao University of Science and Technology, \\ Qingdao, 266000 P. R. China \\ ${ }^{2}$ Key Laboratory of Coordination Chemistry, Functional Materials in Universities of \\ Shandong (De Zhou University), De Zhou, 253023 P. R. China
}

Corresponding author. E-mail: dashuai_74@163.com.

To Polyhedron 


\begin{abstract}
Mixtures of three new MOFs, $\left[\mathrm{Cu}(\mathrm{Hdpt})(\mathrm{tdc})\left(\mathrm{H}_{2} \mathrm{O}\right)\right]_{\mathrm{n}}(\mathbf{1}),\left\{\left[\mathrm{Cu}_{2}(\mathrm{Hdpt})_{2}(\mathrm{tdc})_{2}\right] \cdot 2 \mathrm{DMF}\right\}_{\mathrm{n}}(\mathbf{2})$ and $\quad\left[\mathrm{Cu}_{2}(\mathrm{dpt})(\mathrm{tdc})\right]_{\mathrm{n}} \quad$ (3) $\quad\left(\mathrm{H}_{2} \mathrm{tdc}=\right.$ thiophene-2,5-dicarboxylic $\quad$ acid, Hdpt=4,4'-(1H-1,2,4-triazole-3,5-diyl)bis-Pyridine), have been prepared by hydrothermal method and characterized by single-crystal X-ray diffraction, powder X-ray diffraction (PXRD), IR, TGA, and EA. Through precisely modulating the reaction conditions, pure samples of the three MOFs could be separately obtained, and regularity of reaction conditions impacting the resulted product was founded as well. Interestingly, it reveals that under moderate temperature and high $\mathrm{DMF} / \mathrm{H}_{2} \mathrm{O}$ ratio, 1 firstly crystalized very quickly, and gradually transformed to $\mathbf{3}$ as time grows, which could be eye-monitored and demonstrated by PXRD as well. Moreover, the gas adsorption properties have also been investigated, which show potential applications in gas storage and separation. This work may set an example for the controllable synthesis of MOFs in systems that easily afford mixed-crystals.
\end{abstract}

\title{
Keywords
}

Metal-organic frameworks; Synthesis; Crystal structure; Structure transformation; Gas adsorption 


\section{Introduction}

Metal-organic frameworks (MOFs) are a kind of newly emerged crystalline porous material, which are assembled by the coordination of inorganic metal ions/clusters and organic linkers. Sharply increasing attention in the past two decades is helping MOFs fuel a boom in research and development [1-2]. Owing to their tunable pore structures [3, 4] and excellent chemical/physical properties, MOFs could be potentially used as functional materials in various domains [5], such as gas storage, separation [6-9], catalysis [10-13], sensing [14-17] and drug delivery [18-21]. However, to apply MOFs for practical utilization, the effective synthesis is still a big challenge and should be the prime concern, since high productivity and purity would be needed for the subsequent property studies. On the other hand, the flexibility and diversity of coordination modes of the metal part and organic ligand often lead to the formation of a variety of MOFs with different structures and properties in the same reaction system, which make it very difficult to separate them from each other, thus restricting their application. This problem is common but undesired. Therefore, study on the controllable synthesis of MOFs with desired structures and properties is of great necessity and could be helpful in comprehending the assembly process of MOFs so that exploiting the performances of MOFs will be more freely.

Some recent developed methods showed demonstrations for solving this issue, such as solvent-assisted separation of mixed MOFs based on the density difference and seed-mediated synthesis of phase-pure MOFs, which encouraged us for more investigations in this field [22-25]. As we know, there are many other factors impacting the reaction process, for example, temperature, $\mathrm{pH}$, solvent ratio, time, respectively or a synergistic combination of them. Especially in the systems that easily afford mixed-MOFs, great attention should be paid on all the possible influence factors for minor changes may cause different results.

In this paper, three new MOFs, namely, $\left[\mathrm{Cu}(\mathrm{Hdpt})(\mathrm{tdc})\left(\mathrm{H}_{2} \mathrm{O}\right)\right]_{\mathrm{n}}$ $\left\{\left[\mathrm{Cu}_{2}(\mathrm{Hdpt})_{2}(\mathrm{tdc})_{2}\right] \cdot 2 \mathrm{DMF}\right\}_{\mathrm{n}}(\mathbf{2})$ and $\left[\mathrm{Cu}_{2}(\mathrm{dpt})(\mathrm{tdc})\right]_{\mathrm{n}}(\mathbf{3})$, have been synthesized as crystal mixtures using the same ligands thiophene-2,5-dicarboxylic acid $\left(\mathrm{H}_{2} \mathrm{tdc}\right)$ and 4,4'-(1H-1,2,4-triazole-3,5-diyl)bis-Pyridine (Hdpt) and metal ions $\mathrm{Cu}\left(\mathrm{CH}_{3} \mathrm{COO}\right)_{2} \cdot \mathrm{H}_{2} \mathrm{O}$ under one reaction system [26-29]. Through precisely modulating the reaction conditions, pure samples of the three MOFs could be separately obtained, and regularity of reaction conditions impacting the 
resulted product was founded as well: two drops of $\mathrm{HBF}_{4}$ are essential for the synthesis of these MOFs; low temperature and low water content tends to generate $\mathbf{1}$ with a two dimensional (2D) structure; high temperature and low water content benefited the formation of $\mathbf{3}$ with a 3D porous framework; high water content help to obtain 2 with a 3D framework. Interestingly, it reveals that under moderate temperature and high $\mathrm{DMF} / \mathrm{H}_{2} \mathrm{O}$ ratio 1 crystalized firstly, and gradually transformed to $\mathbf{3}$ as time grows. This work may set an example for the controllable synthesis of MOFs in systems that easily afford mixed-crystals. Herein, we report the controllable synthesis of three metal-organic frameworks. Moreover, the gas adsorption properties have also been investigated, which show potential applications in gas storage and separation.

\section{Experimental}

\subsection{Materials and methods}

All the chemical reagent of analytical grade were commercially available, and used without further purification. The Elementar Vario Micro Cube analyzer was used to carry out the elemental analyses (C, H, N). Infrared (IR) spectrometric analyzer were were measured on a Thermo Nicolet IR200 FT-IR spectrometer using KBr pellets (range of 4000-500 $\mathrm{cm}^{-1}$ ). A SHIMADZU DTG-60 thermo analyzer was used to perform the thermogravimetric analyses (TGA) under nitrogen at a heating rate of $5{ }^{\circ} \mathrm{C} \min ^{-1}$ from room temperature to $700{ }^{\circ} \mathrm{C}$. Powder X-ray diffraction (PXRD) data under the $2 \theta$ range $5-50^{\circ}$ were recorded using $\mathrm{Cu}-\mathrm{K} \alpha$ radiation $(\mathrm{k}=0.1542 \mathrm{~nm})$ on a Bruker D8A A25 X-ray diffractometer, with the X-ray tube operated at $40 \mathrm{kV}$ and $40 \mathrm{~mA}$ at room temperature. $\mathrm{N}_{2}, \mathrm{H}_{2}, \mathrm{CO}_{2}$ and $\mathrm{CH}_{4}$ adsorption measurements were performed on an Autosorb-3.0 (Quantachrome) volumetric analyzer and the $\mathrm{N}_{2}, \mathrm{H}_{2}, \mathrm{CO}_{2}, \mathrm{CH}_{4}$ gases were of $99.999 \%$ purity quality.

\subsection{Preparation of the complexes}

The three complexes could be afforded by the solvothermal reactions of Hdpt, $\mathrm{H}_{2} \mathrm{tdc}$ and $\mathrm{Cu}\left(\mathrm{CH}_{3} \mathrm{COO}\right)_{2} \cdot \mathrm{H}_{2} \mathrm{O}$ in a $\mathrm{HBF}_{4}$ added solvent of DMF and $\mathrm{H}_{2} \mathrm{O}$ under certain range of temperature. Synthesis of the pure samples are as follows.

\subsubsection{Synthesis of pure samples of $\left[\mathrm{Cu}(\mathrm{Hdpt})(\mathrm{tdc})\left(\mathrm{H}_{2} \mathrm{O}\right)\right]_{\mathrm{n}}(\mathbf{1})$}

In a $20 \mathrm{~mL}$ glass vial, $19.9 \mathrm{mg}$ of $\mathrm{Cu}\left(\mathrm{CH}_{3} \mathrm{COO}\right)_{2} \cdot \mathrm{H}_{2} \mathrm{O}(0.1 \mathrm{mmol}), 11.2 \mathrm{mg}$ of $\mathrm{Hdpt}(0.05 \mathrm{mmol})$ and $8.6 \mathrm{mg}$ of $\mathrm{H}_{2}$ tdc $(0.05 \mathrm{mmol})$ were dissolved in mixed solvent of DMF $(5.5 \mathrm{~mL})$ and $\mathrm{H}_{2} \mathrm{O}(0.5$ 
$\mathrm{mL}$ ). Then, 2 drops $\mathrm{HBF}_{4}$ (50 wt $\%$ aqueous solution) was added into mixture and stirred. The vial was sealed and placed in a $55{ }^{\circ} \mathrm{C}$ oven for 2 days. Blue block crystals of 1 were obtained in $46 \%$ yield (based on $\mathrm{Cu}$ ), washed with DMF and air dried. Elemental anal. Calcd for $\mathrm{C}_{18} \mathrm{H}_{13} \mathrm{CuN}_{5} \mathrm{O}_{5} \mathrm{~S}$

(\%): C, 45.52; H, 2.76; N, 14.75; Found: C, 45.98; H, 3.07; N, 14.43. IR (KBr, $\left.\mathrm{cm}^{-1}\right): 3430(\mathrm{~s})$, 2362(w), 1653(s), 1619(s), 1574(s), 1525(m), 1385(s), 1359(s), 1101(m), 1026(w), 992(w), 852(w), 776(w), 727(w), 668(w), 518(w).

\subsubsection{Synthesis of pure samples of $\left\{\left[\mathrm{Cu}_{2}(\mathrm{Hdpt})_{2}(\mathrm{tdc})_{2}\right] \cdot 2 \mathrm{DMF}\right\}_{\mathrm{n}}(\mathbf{2})$}

In a $20 \mathrm{~mL}$ glass vial, $19.9 \mathrm{mg}$ of $\mathrm{Cu}\left(\mathrm{CH}_{3} \mathrm{COO}\right)_{2} \cdot \mathrm{H}_{2} \mathrm{O}(0.1 \mathrm{mmol}), 11.2 \mathrm{mg}$ of $\mathrm{Hdpt}(0.05 \mathrm{mmol})$ and $8.6 \mathrm{mg}$ of $\mathrm{H}_{2}$ tdc $(0.05 \mathrm{mmol})$ were dissolved in mixed solvent with DMF $(1 \mathrm{~mL})$ and $\mathrm{H}_{2} \mathrm{O}(5$ $\mathrm{mL})$. Then, 2 drops $\mathrm{HBF}_{4}(50 \mathrm{wt}$. \% aqueous solution) was added into mixture and stirred. The vial was sealed and placed in a $100{ }^{\circ} \mathrm{C}$ oven for 5 hours. Aquamarine blue block crystals of 2 were obtained in $46 \%$ yield (based on $\mathrm{Cu}$ ), washed with DMF and air dried. Elemental anal. Calcd for $\mathrm{C}_{42} \mathrm{H}_{36} \mathrm{Cu}_{2} \mathrm{~N}_{12} \mathrm{O}_{10} \mathrm{~S}_{2}(\%): \mathrm{C}, 47.59 ; \mathrm{H}, 2.13 ; \mathrm{N}, 13.46$; Found: C, 47.44; H, 2.31; N, 13.52. IR (KBr, $\left.\mathrm{cm}^{-1}\right)$ : 3425(s), 2922(w), 1676(m), 1617(s), 1577(s), 1450(w), 1381(m), 1356(s), 1332(m), 1089(m), 1024(w).

\subsubsection{Synthesis of pure samples of $\left[\mathrm{Cu}_{2}(\mathrm{dpt})(\mathrm{tdc})\right]_{\mathrm{n}}(\mathbf{3})$}

In a $20 \mathrm{~mL}$ glass vial, $19.9 \mathrm{mg}$ of $\mathrm{Cu}\left(\mathrm{CH}_{3} \mathrm{COO}\right)_{2} \cdot \mathrm{H}_{2} \mathrm{O}(0.1 \mathrm{mmol}), 11.2 \mathrm{mg}$ of $\mathrm{Hdpt}(0.05 \mathrm{mmol})$ and $8.6 \mathrm{mg}$ of $\mathrm{H}_{2} \mathrm{tdc}(0.05 \mathrm{mmol})$ were dissolved in mixed solvent with DMF (5.5 $\left.\mathrm{mL}\right)$ and $\mathrm{H}_{2} \mathrm{O}$ (0.5 mL). Then, 2 drops $\mathrm{HBF}_{4}$ (50 wt. \% aqueous solution) was added into mixture and stirred. The vial was sealed and placed in an $85^{\circ} \mathrm{C}$ oven for 3 days. Dark blue block crystals of $\mathbf{3}$ were obtained in $42 \%$ yield (based on $\mathrm{Cu}$ ), washed with DMF and air dried. Elemental anal. Calcd for $\mathrm{C}_{18} \mathrm{H}_{11} \mathrm{Cu}_{2} \mathrm{~N}_{5} \mathrm{O}_{4} \mathrm{~S}(\%): \mathrm{C}, 41.54 ; \mathrm{H}, 2.13 ; \mathrm{N}, 13.46$; Found: $\mathrm{C}, 42.01 ; \mathrm{H}, 2.31 ; \mathrm{N}, 13.52$. IR (KBr, $\left.\mathrm{cm}^{-1}\right)$ : 3448(s), 2362(w), 2339(w), 1652(s), 1620(s), 1560(m), 1487(m), 1094(s), 935(w), 843(w), $546(\mathrm{~m})$.

\subsection{X-ray Structure Determination and Structure Refinement}

X-ray diffraction data of the single crystals was collected on a Bruker SMART APEXII CCD diffractometer equipped with a graphite monochromated Mo K $\alpha$ radiation $(\lambda=0.71073 \AA)$. The SADABS programs was used to apply the empirical absorption correction. Direct methods and full-matrix least-squares methods on $\mathrm{F}^{2}$ were performed to solve and refine the structure using the 
program SHEXL-2014 [30, 31]. The single suite Olex2 [32] was used as an integrated system for all the crystallographic programs. All non-hydrogen atoms were refined anisotropically. The hydrogen atoms which positions and thermal parameters were fixed during the structure refinement were located by geometrically calculations. The crystallographic data and details of selected bond lengths and angles are summarized in Table S1 and Table S2, respectively. For complexes, the volume fractions of disordered solvent in the pores could not be modelled in terms of atomic sites and were treated using the SQUEEZE routine in the PLATON [33] software package.

\subsection{Gas adsorption measurement}

Before gas adsorption measurements, the as-synthesized samples of $\mathbf{1 , 2}$ and $\mathbf{3}$ were soaked in methanol for 3 days and in anhydrous dichloromethane for another 3 days to exchange the solvent molecules involved their frameworks. The samples were collected by decanting and dried in air. Before the gas adsorption tests, solvent-exchanged samples were loaded in a sample tube and further activated under high vacuum at an optimized temperature of $30^{\circ} \mathrm{C}$ for $6 \mathrm{~h}$. Finally, $112 \mathrm{mg}$ (1), $97 \mathrm{mg}$ (2) and $78 \mathrm{mg}$ (3) of degassed samples were used for gas sorption measurements. The gas adsorption isotherm measurements were proceeded at $77 \mathrm{~K}$ in a liquid nitrogen bath, at $273 \mathrm{~K}$ in an ice-water bath and at $298 \mathrm{~K}$ in a water bath.

\section{Results and Discussion}

\subsection{Crystal Structure Description}

(Insert Fig.1)

\subsection{1 $\left[\mathrm{Cu}(\mathrm{Hdpt})(\mathrm{tdc})\left(\mathrm{H}_{2} \mathrm{O}\right)\right]_{\mathrm{n}}(\mathbf{1})$}

Structure analysis reveals that complex $\mathbf{1}$ crystallized in the monoclinic system with space group P21/c. The asymmetric unit of complex 1 contains one $\mathrm{Cu}(\mathrm{II})$ ion, one $\mathrm{tdc}^{2-}$ ligand, one Hdpt ligand and one water molecule. In compound $\mathbf{1}, \mathrm{Cu}(\mathrm{II})$ ion is coordinated by four $\mathrm{O}$ atoms of which three are from different $\mathrm{tdc}^{2-}$ ligands and one from water molecule, and two pyridyl $\mathrm{N}$ atoms from Hdpt ligand to form an atactic octahedron geometry (Fig. 1a). The $\mathrm{Cu}-\mathrm{O}$ bond distances are in the range of 1.945(2)-2.284(3) $\AA$, and the $\mathrm{Cu}-\mathrm{N}$ bond distance is 2.019(3) $\mathrm{A}$. The bond angles between the donor atoms around the $\mathrm{Cu}$ (II) center range from 87.84(10) to 168.32(12) (Table S2). As shown in Fig. 2, different linear organic ligands $\left(\operatorname{tdc}^{2-}\right.$ and $\left.\mathrm{Hdpt}\right)$ connect to each other by centering on the 
single $\mathrm{Cu}(\mathbb{I})$, and form a typical grid layer structure. These grid structures further generate a reticular 3D supramolecular structure through hydrogen bonds with 1D channels along $a$ and $c$ axis, and the porosity ratio of the complex was $51.7 \%$ after removing the solvent molecules as estimated by PLATON.

(Insert Fig.2)

\subsection{2 $\left\{\left[\mathrm{Cu}_{2}(\mathrm{Hdpt})_{2}(\mathrm{tdc})_{2}\right] \cdot 2 \mathrm{DMF}\right\}_{\mathrm{n}}(\mathbf{2})$}

Single-crystal structure analysis reveals that complex 2 crystallized in the $\mathrm{P} 2 / 1 \mathrm{n}$ space group of monoclinic system. The asymmetric unit of 2 consists of two $\mathrm{Cu}(\mathrm{II})$ ions, two Hdpt ligands and two $\operatorname{tdc}^{2-}$ ligands. $\mathrm{Cu} 1$ and $\mathrm{Cu} 2$ ions are all five-coordinated with similar coordination environments, which are bridged by a pair of carboxyl oxygen groups to form a binuclear $\mathrm{Cu}$ (II) unit. $\mathrm{Cu} 1$ ion is surrounded by three carboxyl oxygen atoms from three different $\operatorname{tdc}^{2-}$ ligands and two nitrogen atom from three different Hdpt ligands (Fig. 1b). The Cu1-O bond distances are in the range of 1.982(2)-2.270(3) $\AA$ and the Cu1-N distances are 2.010(3)-2.026(3) ̊ respectively, indicating that the geometry of $\mathrm{Cu} 1$ ion is nearly in between square pyramid and trigonal bipyramid. $\mathrm{Cu} 2$ ion has a similar coordination environment with $\mathrm{Cu} 1$, with the $\mathrm{Cu} 2-\mathrm{O}$ and $\mathrm{Cu} 2-\mathrm{N}$ bond distances in the range of 1.971(2)-2.358(3) and 2.014(3)-2.010(3) respectively (Table S2). Interestingly, there contains internal cavities instead of open channels, which was caused by the formation of helical chains inside the framework. As shown in Fig. 3, the cavity was composed of alternating unit of three pairs of Hdpt ligand, four $\mathrm{Cu}(\mathrm{II})$ clusters and two pairs of $\operatorname{tdc}^{2-}$ ligands, with the help of hydrogen bonds. Inside the cavity was encapsulated one DMF molecule, just like a snake hunting for its food. So, although no obvious channels could be found along with all directions of the structure, it still has a void volume of $25.4 \%$, which is estimated by the PLATON software.

(Insert Fig.3)

\subsection{3 $\left[\mathrm{Cu}_{2}(\mathrm{dpt})(\mathrm{tdc})\right]_{\mathrm{n}}(\mathbf{3})$}

Single-crystal structure analysis reveals that complex $\mathbf{3}$ crystallized in the orthorhombic system with space group Pccn. The asymmetric unit of complex $\mathbf{3}$ contains two mixed-valence $\mathrm{Cu}(\mathrm{I} / \mathrm{II})$ ions [6-connected $\mathrm{Cu} 1(\mathrm{II})$ and 2-connected $\mathrm{Cu} 2(\mathrm{I})]$, one tdc ${ }^{2-}$ ligand, and one dpt ${ }^{-}$ligand. In complex $3, \mathrm{Cu} 1$ (II) ion is coordinated by four $\mathrm{O}$ atoms from different $\operatorname{tdc}^{2-}$ ligands and two $\mathrm{N}$ atoms of pyridyl from different dpt ligand to form an octahedral geometry (Fig. 1c). The Cu1(II)-O bond 
distances are in the range of 1.917(4)-2.363(6) $\AA$. The bond angles between the donor atoms around the Cu1(II) center range from 58.42(17) to 170.0(3) (Table S2.). The in-situ formed Cu2(I) reveals a nearly linear coordinate mode (angles: 170.37) connecting two $\mathrm{N}$ atoms of triazole groups from different dpt ligands. The $\mathrm{Cu}(\mathrm{I})-\mathrm{N}$ bond $[\mathrm{Cu}(2)-\mathrm{N}(3) \# 5-1.881(5)$ and $\mathrm{Cu}(2)-\mathrm{N}(4)-1.831(5)]$ is shorter than the $\mathrm{Cu}(\mathrm{II})-\mathrm{N}$ bond $[\mathrm{Cu}(1)-\mathrm{N}(5) \# 3-2.014(5)$ and $\mathrm{Cu}(1)-\mathrm{N}(1)-2.007(5)]$, which are similar to those found in coordination polymers. As shown in Fig. 4a, each dpt ligand connects four $\mathrm{Cu}(\mathrm{I} / \mathrm{II})$ ion, of which $\mathrm{N} 1$ and N5 of pyridyl groups link two Cu1(II) with N3 and N4 linking two $\mathrm{Cu} 2$ (I) ions, leading to a 2-D grid-like layer structure (as layers), while each tdc ${ }^{2-}$ ligand (as pillars) connects the two Cu1(II) atoms of the adjacent layers to generate a 3D "pillar-layer" structure. On the other hand, the overall structure of $\mathbf{3}$, which shows a 3D porous framework, also could be simplified into an infinite (4,4)-connected cds topological network with a Schläfli symbol $\left(6^{5} .8\right)$ (Fig. 4c), if taking the $\mathrm{dpt}^{-}$ligand and the Cu1(II) atom as 4-connected nodes respectively. In addition, looking along the $c$ direction of the framework, two kinds of rectangular pores (Fig. 4b) could be observed with distinct sizes. The B-type pores has a size of $4.6 \times 10.3 \AA$, which is a little bigger than the A-type ones $(4.5 \times 8.6 \AA)$, considering the van der Waals radius of atoms. Moreover, the accessible volume of complex is $51.4 \%$, estimated by PLATON.

(Insert Fig.4)

\subsection{Synthesis and structure transformation}

Working on the controllable synthesis of targeted MOFs, we found that in $\mathrm{DMF} / \mathrm{H}_{2} \mathrm{O} / \mathrm{HBF}_{4}$ surroundings, the solvothermal reactions of $\mathrm{Hdpt}$ and $\mathrm{H}_{2} \mathrm{tdc}$ ligands with $\mathrm{Cu}^{2+}$ tend to generate three different frameworks, that is compound $\mathbf{1 , 2}$ and $\mathbf{3}$. As a result, normally the output products are mixture crystals of these MOFs. To purify these MOFs from each other, much more precise modulation of the reaction conditions were explored, which has been listed in table 1. Regularity of products was observed that 1) two drops of $\mathrm{HBF}_{4}$ are essential for the synthesis of these MOFs (no crystals would be gained without $\mathrm{HBF}_{4}$ ); 2) low temperature and low water content tend to generate $\mathbf{1}$ with a 2D layer structure; 3) high temperature and low water content benefit the formation of $\mathbf{3}$ with a 3D porous framework; 4) high water content helps to obtain the 3D framework of 2 with little effect by temperature.

As we know, higher $\mathrm{pH}$ values could benefit the deprotonation of the ligands, while $\mathrm{Cu}(\mathrm{II})$ ions 
tend to generate precipitate with $\mathrm{pH}$ over 4.7. Therefore, lowing the $\mathrm{pH}$ value by adding a little acid to the system could inhibit the formation of precipitation. Take the synthesis of $\mathbf{2}$ as an example, $\mathrm{pH}$ value of the reaction system is tested to be about 6.0 without adding $\mathrm{HBF}_{4}$, which afford an original mixture of suspension and no crystals were obtained at last (figure S7a). However, the mixture changed into clear solution with the addition of $\mathrm{HBF}_{4}$ at the beginning and crystals would be obtained when the reaction is over (figure S7b). As we try, it seemed that two drops (about $60 \mu \mathrm{L}$ ) of $\mathrm{HBF}_{4}$ is just the best dosage to balance the deprotonation of the ligands and inhibition of precipitation, because the $\mathrm{pH}$ value in this case is just in the range of about 4.0-5.0, which is on or approaching the threshold of precipitation. If keep lowing the $\mathrm{pH}$ value by adding more acid, yield and quality of the crystals will be reduced, which might be attributed to the deprotonation decreasing of the ligands.

Along with $\mathrm{DMF} / \mathrm{H}_{2} \mathrm{O}$ ratio increasing and temperature declining, productivity of $\mathbf{1}$ increased gradually, and pure samples of 1 could be obtained below $65^{\circ} \mathrm{C}$ when the solvent ratio is 5.5:0.5. Subsequently, blue-green crystals of 2 could be purified by reducing DMF/ $\mathrm{H}_{2} \mathrm{O}$ ratio to $2: 4$ in the given temperature ranges, with color changing to blue if keeping lowering the ratio. As for $\mathbf{3}$, a condition of temperature $>85{ }^{\circ} \mathrm{C}$ could yield pure samples with a $\mathrm{DMF} / \mathrm{H}_{2} \mathrm{O}$ ratio of 5.5:0.5.

Interestingly, it reveals that under moderate temperature $\left(75 \sim 85^{\circ} \mathrm{C}\right)$ and high $\mathrm{DMF} / \mathrm{H}_{2} \mathrm{O}$ ratio (5.5:0.5 5:1) bulk crystals of 1 crystalized quickly within about two hours, while gradually transformed to $\mathbf{3}$ as time grows. The transformation process could be monitored through PXRD patterns of the time-varying product (Fig. 6). Importantly, "transition state crystals" could be clearly observed as seen from picture of the product at eight hours — dark blue crystals of $\mathbf{1}$ was gradually fading, cracking and changing into crystals of $\mathbf{3}$. This time-dependent single crystal to single crystal (SC-SC) [34-36] structure transformations is very rare in MOFs, so far as we know. Possible reasons for this unique transformation might be explained through comparison between the two structures that: 1) under this condition, $\mathbf{1}$ could be yield very fast with the existence of massive $\mathrm{Cu}^{2+} ; 2$ ) as time goes by, part of the excessive $\mathrm{Cu}^{2+}$ was reduced into $\mathrm{Cu}^{+}$, which was then absorbed into the spaces among the layers of $1 ; 3$ ) the in-situ formed $\mathrm{Cu}^{+}$induce a slight adjustment of the layer structures and then link the 2D layers into the 3D porous framework of $\mathbf{3}$ through coordinating with the triazole groups between different layers.

All the results above could be confirmed by the Powder or single-crystal XRD (Fig. 5) and 
crystal images of the products (Table 1).

\author{
(Insert Fig.5) \\ (Insert Fig.6) \\ (Insert Table 1)
}

\title{
3.3 PXRD
}

As shown in Figure S1, PXRD patterns of the pure samples of $\mathbf{1}, \mathbf{2}$ and $\mathbf{3}$ agree well with their simulated ones, respectively, indicating the pure phases of these solid-state samples and further confirming the successful separation of the three frameworks. Moreover, the samples after solvent exchanged and gas adsorption are still as crystalline as the pure samples of the three compounds as proven by the PXRD patterns, suggesting the good stability of the three frameworks.

\subsection{Gas adsorption}

\section{(Insert Fig.7)}

In order to characterize the porosity, $\mathrm{N}_{2}$ adsorption-desorption isotherms was measured at $77 \mathrm{~K}$ for activated samples of the three MOFs. As shown in Fig. 7a, complex 3 exhibit type I sorption isotherms, suggesting the microporosity of this material. The maximum $\mathrm{N}_{2}$ uptake is around 235.9 $\mathrm{cm}^{3} \mathrm{~g}^{-1}$ (STP) at $77 \mathrm{~K}$ and 1.0 bar for 3. Based on the $\mathrm{N}_{2}$ sorption data, the Brunauer-Emmett-Teller (BET) and Langmuir surface areas of complex 3 are estimated to be 793.5 and $832.8 \mathrm{~m}^{2} \mathrm{~g}^{-1}$, respectively. Moreover, the calculated H-K (Horvath-Kawazoe) pore size distributions range from 3.5 to $11.4 \AA$, corresponding to the pore sizes evaluated from the single-crystal X-ray structure. The pore volumes calculated from the maximum $\mathrm{N}_{2}$ uptakes are $0.310 \mathrm{~cm}^{3} \mathrm{~g}^{-1}$ for complex $\mathbf{3}$ which are close to the theoretical values of $0.322 \mathrm{~cm}^{3} \mathrm{~g}^{-1}$ calculated using PLATON software. In addition, compared with 3, complex $\mathbf{1}$ and $\mathbf{2}$ are much less porous (Fig. 7a and Fig. S3).

The porous nature of $\mathbf{3}$ lead us to further investigate its capture and separation properties for other gases including $\mathrm{CO}_{2}, \mathrm{CH}_{4}$ and $\mathrm{H}_{2}$. As shown in Fig. 7 b and c, 3 could uptake a moderate amount of $\mathrm{CO}_{2}$ up to $95.7 \mathrm{~cm}^{3} \mathrm{~g}^{-1}(273 \mathrm{~K})$ and $53.5 \mathrm{~cm}^{3} \mathrm{~g}^{-1}(298 \mathrm{~K})$, while the uptake amounts of $\mathrm{CH}_{4}$ are $35.1 \mathrm{~cm}^{3} \mathrm{~g}^{-1}(273 \mathrm{~K})$ and $16.7 \mathrm{~cm}^{3} \mathrm{~g}^{-1}(298 \mathrm{~K})$ at $1 \mathrm{~atm}$, respectively. In spite of that the similar calculated void volumes between $\mathbf{1}$ and $\mathbf{3}$, complex $\mathbf{1}$ reveals much less uptake amounts of $\mathrm{CO}_{2}$ and $\mathrm{CH}_{4}$, that is, $42.9 \mathrm{~cm}^{3} \mathrm{~g}^{-1}(273 \mathrm{~K})$ and $23.7 \mathrm{~cm}^{3} \mathrm{~g}^{-1}(298 \mathrm{~K})$ for $\mathrm{CO}_{2}$, and $16.6 \mathrm{~cm}^{3} \mathrm{~g}^{-1}(273 \mathrm{~K})$ and 5.8 $\mathrm{cm}^{3} \mathrm{~g}^{-1}(298 \mathrm{~K})$ for $\mathrm{CH}_{4}$ at $1 \mathrm{~atm}$. In addition, $\mathrm{CO}_{2}$ isosteric heats of adsorption $\left(Q_{\mathrm{st}}\right)$ for $\mathbf{1}$ and $\mathbf{3}$ were calculated based on the respective adsorption isotherms at $273 \mathrm{~K}$ and $298 \mathrm{~K}$ by employing the 
Clausius-Clapeyron equation [37, 38]. The calculated $Q_{\mathrm{st}}$ values range is $58.1 \sim 30.5 \mathrm{~kJ} \mathrm{~mol}^{-1}$ for $\mathbf{1}$ and 17.7 28.8 $\mathrm{kJ} \mathrm{mol}^{-1}$ for $\mathbf{3}$, respectively, depending on the gas loading. Moreover, gas adsorptions of $\mathbf{1}$ and $\mathbf{3}$ both exhibit significantly different uptakes towards $\mathrm{CO}_{2}$ and $\mathrm{CH}_{4}$ at both 273 and $298 \mathrm{~K}$. So the initial slopes of their adsorption isotherms were calculated over very low pressure ranges in order to estimate the $\mathrm{CO}_{2}$ adsorption selectivity of them towards $\mathrm{CH}_{4}$ (Fig. $\mathrm{S} 4 \mathrm{a}$ and b). The result $\mathrm{CO}_{2} / \mathrm{CH}_{4}$ selectivity is calculated to be $4.4: 1$ at $273 \mathrm{~K}$ and 4.0:1 at $298 \mathrm{~K}$, which is comparable to many reported MOFs $[39,40]$. As for complex $\mathbf{2}$, almost no adsorption was obtained, which might be attributed to the reason that the twisted (non-open) channels with smaller sizes inside the framework extremely limited the entrance of $\mathrm{CO}_{2}$ and $\mathrm{CH}_{4}$ molecules with bigger sizes, given its low assessable volume.

In addition, $\mathrm{H}_{2}$ storage capacity was also measured under low pressure. As shown in Fig. $7 \mathrm{~d}$, the amount of $\mathrm{H}_{2}$ uptake at $77 \mathrm{~K}$ for 1,2 and 3 is $54.2(0.5 \mathrm{wt} \%), 83.2(0.7 \mathrm{wt} \%)$ and $176.5(1.6 \mathrm{wt} \%)$ $\mathrm{cm}^{3} \mathrm{~g}^{-1}$, respectively. Interestingly, although $\mathbf{2}$ is lower porous than 1, it has a little higher $\mathrm{H}_{2}$ uptake amount. Contrary to the case of $\mathrm{CO}_{2}$ and $\mathrm{CH}_{4}$ adsorption, the narrow twisted channels and internal cavities are just suitable for $\mathrm{H}_{2}$ entrance and storage, thus enhancing the $\mathrm{H}_{2}$ uptake ability of 2 . However, it should be pointed out that the $\mathrm{H}_{2}$ uptake capacity of $\mathbf{2}$ is still far lower than $\mathbf{1}$, which is mainly caused by the low porosity of $\mathbf{2}$.

\section{Conclusions}

In summary, three new copper-organic frameworks with same ligands have been successfully separated from one reaction system, through precisely modulating the reaction conditions (temperature, $\mathrm{pH}$, solvent ratio, time). Regularity of reaction conditions impacting the resulted product was founded as well. Importantly, an uncommon time-dependent SC-SC structure transformation could happen from $\mathbf{1}$ to $\mathbf{3}$ under suitable conditions. The transforming process was investigated and a possible mechanism was proposed as well. Moreover, the gas adsorption properties have also been investigated, which show potential applications in gas storage and separation. This work may pave a way for the controllable synthesis of MOFs in systems that easily afford mixed-crystals.

\section{Acknowledgements}

This study was financially supported by the National Science Foundation of China (21371028; 
21601028 and 21501022).

\section{Appendix A. Supplementary data}

CCDC $1486881 ; 1504982$ and 1486880 contains the supplementary crystallographic data for $\left[\mathrm{Cu}(\mathrm{Hdpt})(\mathrm{tdc})\left(\mathrm{H}_{2} \mathrm{O}\right)\right]_{\mathrm{n}}(\mathbf{1}) ;\left\{\left[\mathrm{Cu}_{2}(\mathrm{Hdpt})_{2}(\mathrm{tdc})_{2}\right] \cdot 2 \mathrm{DMF}\right\}_{\mathrm{n}}(\mathbf{2})$ and $\left[\mathrm{Cu}_{2}(\mathrm{dpt})(\mathrm{tdc})\right]_{\mathrm{n}}(\mathbf{3})$, respectively. These data can be obtained free of charge via http://www.ccdc.cam.ac.uk/conts/retrieving.html, or from the Cambridge Crystallographic Data Centre, 12 Union Road, Cambridge CB2 1EZ, UK; fax: (+44) 1223-336-033; or e-mail: deposit@ccdc.cam.ac.uk. 


\section{References:}

[1] H. C. Zhou, J. R. Long, O. M. Yaghi. Introduction to Metal-Organic Frameworks. Chem. Rev., 112 (2012) 673.

[2] W. Xia, A. Mahmood, R. Q. Zou, Q. Xu. Metal-organic frameworks and their derived nanostructures for electrochemical energy storage and conversion. Energ. Environ. Sci., $8(2015) 1837$.

[3] H. Furukawa, N. Ko, Y. B. Go, N. Aratani, S. B. Choi, E. Choi, A. Ö. Yazaydin, R. Q. Snurr, M. O’Keeffe, J. Kim, O. M. Yaghi. Ultrahigh Porosity in Metal-Organic Frameworks. Science, 329 (2010) 424.

[4] H. K. Chae, D. Y. Siberio-Perez, J. Kim, Y. Go, M. Eddaoudi, A. J. Matzger, M. O'Keeffe, O. M. Yaghi. A route to high surface area, porosity and inclusion of large molecules in crystals. Nature, 427 (2004) 523.

[5] H. Furukawa, K. E. Cordova, M. O'Keeffe, O. M. Yaghi. The Chemistry and Applications of Metal-Organic Frameworks. Science, 341 (2013) 974.

[6] Q. Y. Li, Y. Quan, W. Wei, J. Li, H. Lu, R. Ni, X. J. Wang. Synthesis, crystal structure and gas uptake properties of a urea-functionalized rht-type metal-organic framework. Polyhedron, 99 (2015) 1.

[7] N. L. Rosi, J. Eckert, M. Eddaoudi, D. T. Vodak, J. Kim, M. O'Keeffe, O. M. Yaghi, Hydrogen Storage in Microporous Metal-Organic Frameworks. Science, 300 (2003) 1127.

[8]A. R. Millward, O. M. Yaghi. Metal-Organic Frameworks with Exceptionally High Capacity for Storage of Carbon Dioxide at Room Temperature. J. Am. Chem. Soc., 127 (2005) 17998.

[9] S. Bourrelly, P. L. Llewellyn, C. Serre, F. Millange, T. Loiseau, G. Ferey. Different adsorption behaviors of methane and carbon dioxide in the isotypic nanoporous metal terephthalates MIL-53 and MIL-47. J. Am. Chem. Soc., 127 (2005) 13519.

[10] D. Saha, T. Maity, R. Sen, S. Koner. Heterogeneous catalysis over a barium carboxylate framework compound: Synthesis, X-ray crystal structure and aldol condensation reaction. Polyhedron, 43 (2012) 63.

[11] J. Lee, O. K. Farha, J. Roberts. K. A. Scheidt, S. T. Nguyen, J. T. Hupp. Metal-organic 
framework materials as catalysts. Chem. Soc. Rev., 38 (2009) 1450.

[12] C. D. Wu, A. Hu, L. Zhang, W. B. Lin. Homochiral porous metal-organic framework for highly enantioselective heterogeneous asymmetric catalysis. J. Am. Chem. Soc., 127 (2005) 8940.

[13] U. Mueller, M. Schubert, F. Teich, H. Puetter, K. Schierle-Arndt, J. Pastre. Metal-organic frameworks-prospective industrial applications. J. Mater. Chem., 16 (2006) 626.

[14] Z. C. Hu, B. J. Deibert, J. Li. Luminescent metal-organic frameworks for chemical sensing and explosive detection. Chem. Soc. Rev., 43 (2014) 5815.

[15] B. Gole, A. K. Bar, P. S. Mukherjee. Fluorescent metal-organic framework for selective sensing of nitroaromatic explosives. Chem. Commun., 47 (2011) 12137.

[16] Z. Z. Lu, R. Zhang, Y. Z. Li, Z. J. Guo, H. G. Zheng. Solvatochromic Behavior of a Nanotubular Metal-Organic Framework for Sensing Small Molecules. J. Am. Chem. Soc., 133 (2011) 4172.

[17] H. L. Jiang, Y. Tatsu, Z. H. Lu, Q. Xu. Non-, Micro-, and Mesoporous Metal-Organic Framework Isomers: Reversible Transformation, Fluorescence Sensing, and Large Molecule Separation. J. Am. Chem. Soc., 132 (2010) 5586.

[18] J. Y. An, S. J. Geib, N. L. Rosi. Cation-Triggered Drug Release from a Porous Zinc-Adeninate Metal-Organic Framework. J. Am. Chem. Soc., 131 (2009) 8376.

[19] F. J. Song, C. Wang, J. M. Falkowski, L. Q. Ma, W. B. Lin. Isoreticular Chiral Metal-Organic Frameworks for Asymmetric Alkene Epoxidation: Tuning Catalytic Activity by Controlling Framework Catenation and Varying Open Channel Sizes. J. Am. Chem. Soc., 132 (2010) 15390.

[20] S. T. Meek, J. A. Greathouse, M. D. Allendorf. Metal-Organic Frameworks: A Rapidly Growing Class of Versatile Nanoporous Materials. Adv. Mater., 23 (2011) 249.

[21] R. C. Huxford, J. Della Rocca, W. B. Lin. Metal-organic frameworks as potential drug carriers. Curr. Opin. Chem. Biol., 14 (2010) 262.

[22] H. Q. Xu, K. C. Wang, M. L. Ding, D. W. Feng, H. L. Jiang, H. C. Zhou. Seed-Mediated Synthesis of Metal-Organic Frameworks. J. Am. Chem. Soc., 138 (2016) 5316.

[23] Y. Q. Lan, H. L. Jiang, S. L. Li, Q. Xu. Solvent-Induced Controllable Synthesis, 
Single-Crystal to Single-Crystal Transformation and Encapsulation of Alq3 for Modulated Luminescence in $(4,8)$-Connected Metal-Organic Frameworks. Inorg. Chem., $51(2012) 7484$.

[24] Y. Wang, J. Yang, Y. Y. Liu, J. F. Ma. Controllable Syntheses of Porous Metal-Organic Frameworks: Encapsulation of $\operatorname{Ln}(\mathrm{III})$ Cations for Tunable Luminescence and Small Drug Molecules for Efficient Delivery. Chem.-Eur. J., 19 (2013) 14591.

[25] Q. Chen, Z. Chang, W. C. Song, H. Song, H. B. Song, T. L. Hu, X. H. Bu. A Controllable Gate Effect in Cobalt(II) Organic Frameworks by Reversible Structure Transformations. Angew. Chem. Int. Ed., 52 (2013) 11550.

[26] Y. Lu, Y. Dong, J. Qin. Porous pcu-type Zn(II) framework material with high adsorption selectivity for $\mathrm{CO}_{2}$ over $\mathrm{N}_{2}$. J. Mol. Struct., 1107 (2016) 66.

[27] L. Zhou, C. Wang, X. Zheng, Z. Tian, L. Wen, H. Qu, D. Li. New metal-organic frameworks based on 2,5-thiophenedicarboxylate and pyridine- or imidazole-based spacers: syntheses, topological structures, and properties. Dalton Trans., 46 (2013) 16375

[28] J. Zhang, Y. Lin, X. Huang, X. Chen. From One- to Three-Dimensional Architectures: Supramolecular Isomerism of Copper(I) 3,5-Di(4-pyridyl)-1,2,4-triazolate Involving in Situ Ligand Synthesis. Cryst. Growth. Des., 2 (2006) 519.

[29] X. Xie, S. Chen, Z. Xia, S. Gao. Construction of metal-organic frameworks with transitional metals based on the 3,5-bis(4-pyridyl)-1H-1,2,4-triazole ligand. Polyhedron, 4 (2009) 679.

[30] G. M. Sheldrick. A short history of SHELX. Acta Crystallogr. Sect. A: Found. Crystallogr., 1 (2008) 112.

[31] G. M. Sheldrick. Crystal structure refinement with SHELXL. Acta Crystallogr. Sect. C: Cryst. Struct. Commun, 1 (2015) 3.

[32] O. V. Dolomanov, L. J. Bourhis, R. J. Gildea, J. A. K. Howard, H. Puschmann. OLEX2: a complete structure solution, refinement and analysis program. J. Appl. Crystallogr., 2 (2009) 339.

[33] A. L. Spek. Structure validation in chemical crystallography. Acta Crystallogr. Sect D: Biol. Crystallogr., 2 (2009) 148. 
[34] Q. Chen, Z. Chang, W. C. Song, H. Song, H. B. Song, T. L. Hu, X. H. Bu. A Controllable Gate Effect in Cobalt(II) Organic Frameworks by Reversible Structure Transformations. Angew. Chem. Int. Ed., 52 (2013) 11550.

[35] B. L. Chen, N. W. Ockwig, F. R. Fronczek, D. S. Contreras, O. M. Yaghi. Transformation of a metal-organic framework from the NbO to PtS net. Inorg. Chem., 44 (2005) 181.

[36] X. Z. Song, S. Y. Song, S. N. Zhao, Z. M. Hao, M. Zhu, X. Meng, L. L. Wu, H. J. Zhang. Single-Crystal-to-Single-Crystal Transformation of a Europium(III) Metal-Organic Framework Producing a Multi-responsive Luminescent Sensor. Adv. Funct. Mater., 24 (2014) 4034.

[37] D. Zhong, J. Lin, W. Lu, L. Jiang, T. Lu. Strong Hydrogen Binding within a 3D Microporous Metal - Organic Framework. Inorg. Chem., 48 (2009) 8656.

[38] M. Dincă and J. R. Long. Strong $\mathrm{H}_{2}$ Binding and Selective Gas Adsorption within the Microporous Coordination Solid $\mathrm{Mg}_{3}\left(\mathrm{O}_{2} \mathrm{C}-\mathrm{C}_{10} \mathrm{H}_{6}-\mathrm{CO}_{2}\right)_{3}$. J. Am. Chem. Soc., 127 (2005) 9376.

[39] J. Sim, H. Yim, N. Ko, S. B. Choi, Y. Oh, H. J. Park, S. Y. Park, J. Kim. Gas adsorption properties of highly porous metal-organic frameworks containing functionalized naphthalene dicarboxylate linkers. Dalton Trans., 43 (2014) 18017.

[40] N. T. T. Nguyen, H. Furukawa, F. Gándara, H. T. Nguyen, K. E. Cordova, O. M. Yaghi. Angew. Chem. Int. Ed., 53 (2014) 10645. 


\section{Captions to Figure and Tables}

Table 1. Obtained products under different reaction conditions.

Fig. 1. Coordination environment of the three complexes: 1(a); 2 (b); 3 (c) (most H atoms omitted for clarity).

Fig. 2. The packing diagram of 1 showing the hydrogen bonding interactions (purple dashed lines) and the typical 2D grid structure.

Fig. 3. The semi-closed cage in 2 (Purple molecule on behalf of DMF).

Fig. 4. (a) The $t d c^{2-}$ ligands connect the 2-D grid-like layer structure into a 3D framework; (b) View of the pore alone $c$ axis in a 3D framework of complex 2; (c) Schematic representation of the 4-connected topological net (the purple balls represent four-connected central $\mathrm{Cu}$ atom and green balls represent the four-connected ligand $\mathrm{dpt}^{-}$).

Fig. 5. XRD patterns for the obtained products with different $\mathrm{DMF} / \mathrm{H}_{2} \mathrm{O}$ ratio under temperatures from $55^{\circ} \mathrm{C}$ to $100^{\circ} \mathrm{C}$

Fig. 6. PXRD patterns and crystal images for the obtained products of different time during the transformation processes of 1 to 3 under moderate temperature $\left(75 \sim 85{ }^{\circ} \mathrm{C}\right)$ and high $\mathrm{DMF} / \mathrm{H}_{2} \mathrm{O}$ ratio (5.5:0.5 5:1).

Fig. 7. Gas sorption isotherms for 1, 2and 3: (a) $\mathrm{N}_{2}$ sorption isotherms of 3 at $77 \mathrm{~K}$ (inset, pore size distribution plot); (b) $\mathrm{CO}_{2}$ at $273 \mathrm{~K}$ and $298 \mathrm{~K}$; (c) $\mathrm{CH}_{4}$ at $273 \mathrm{~K}$ and $298 \mathrm{~K}$; (d) $\mathrm{H}_{2}$ at $77 \mathrm{~K}$. 
Table 1.

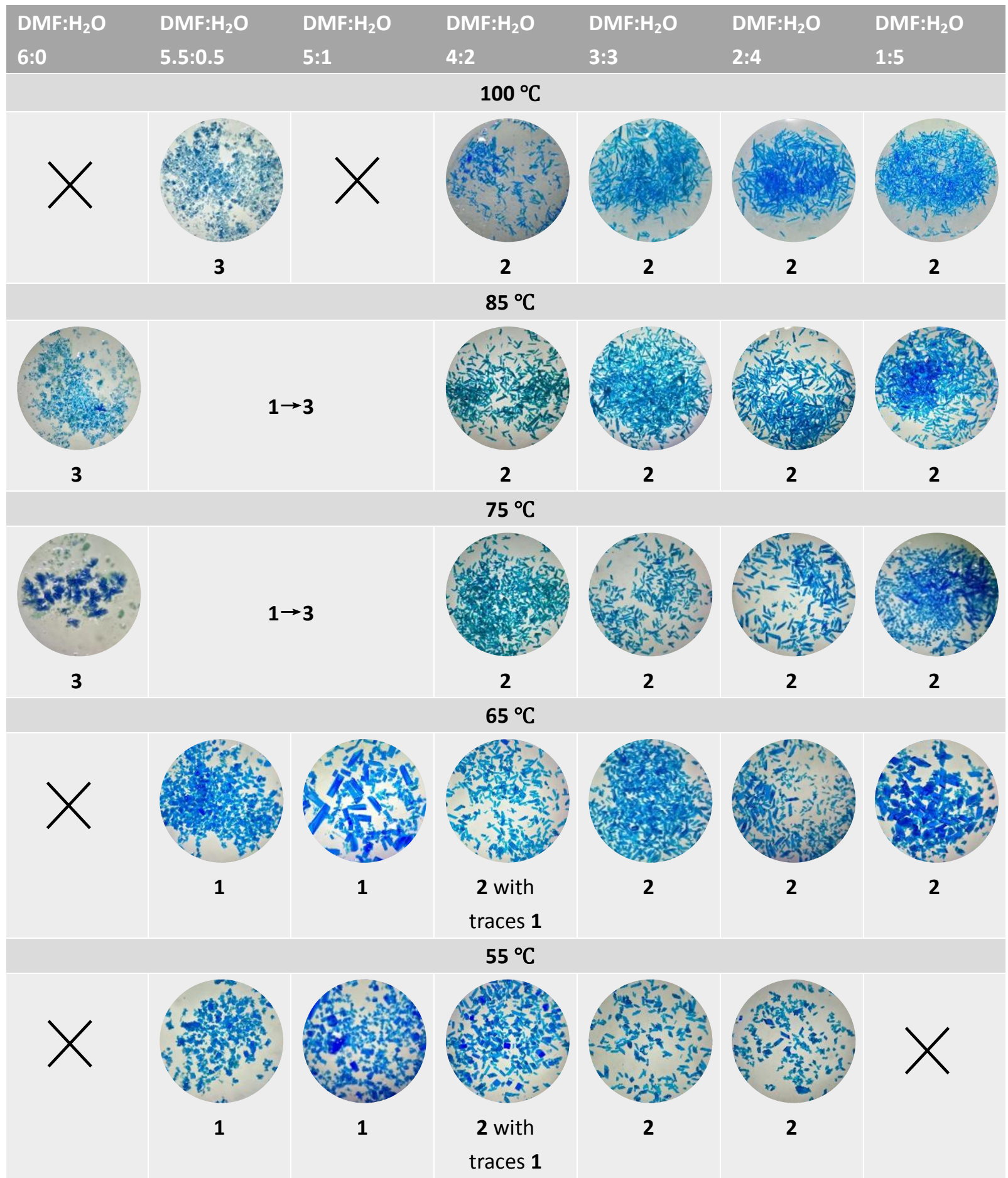

Fig. 1. 


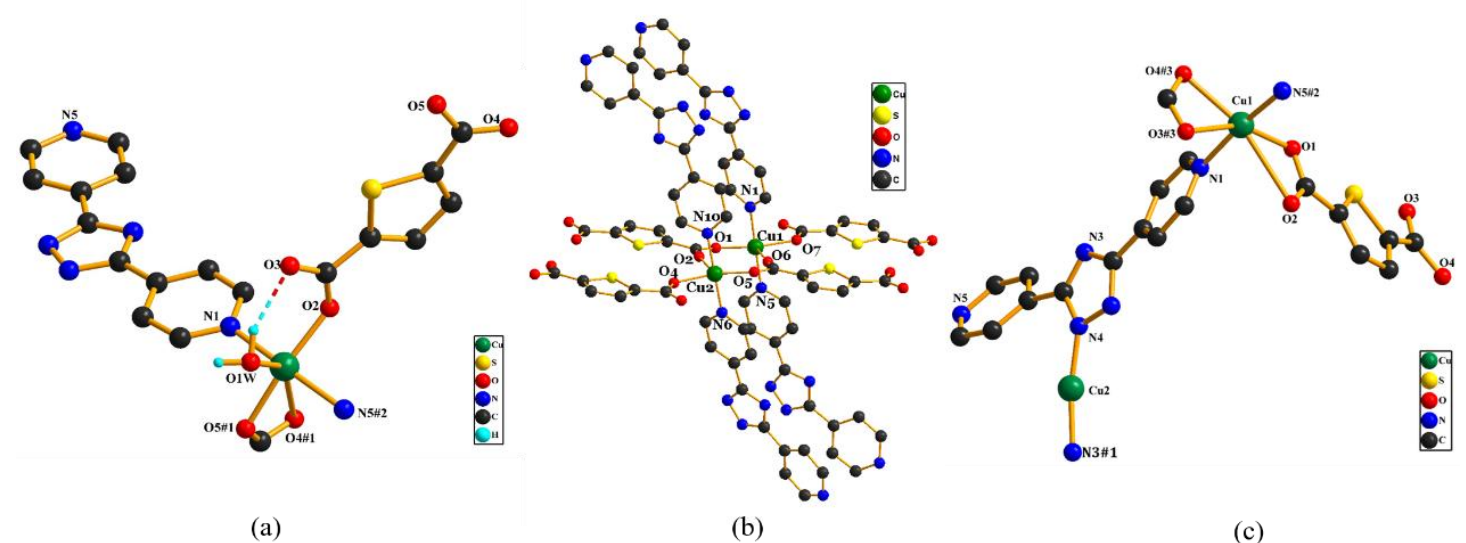

Fig. 2.

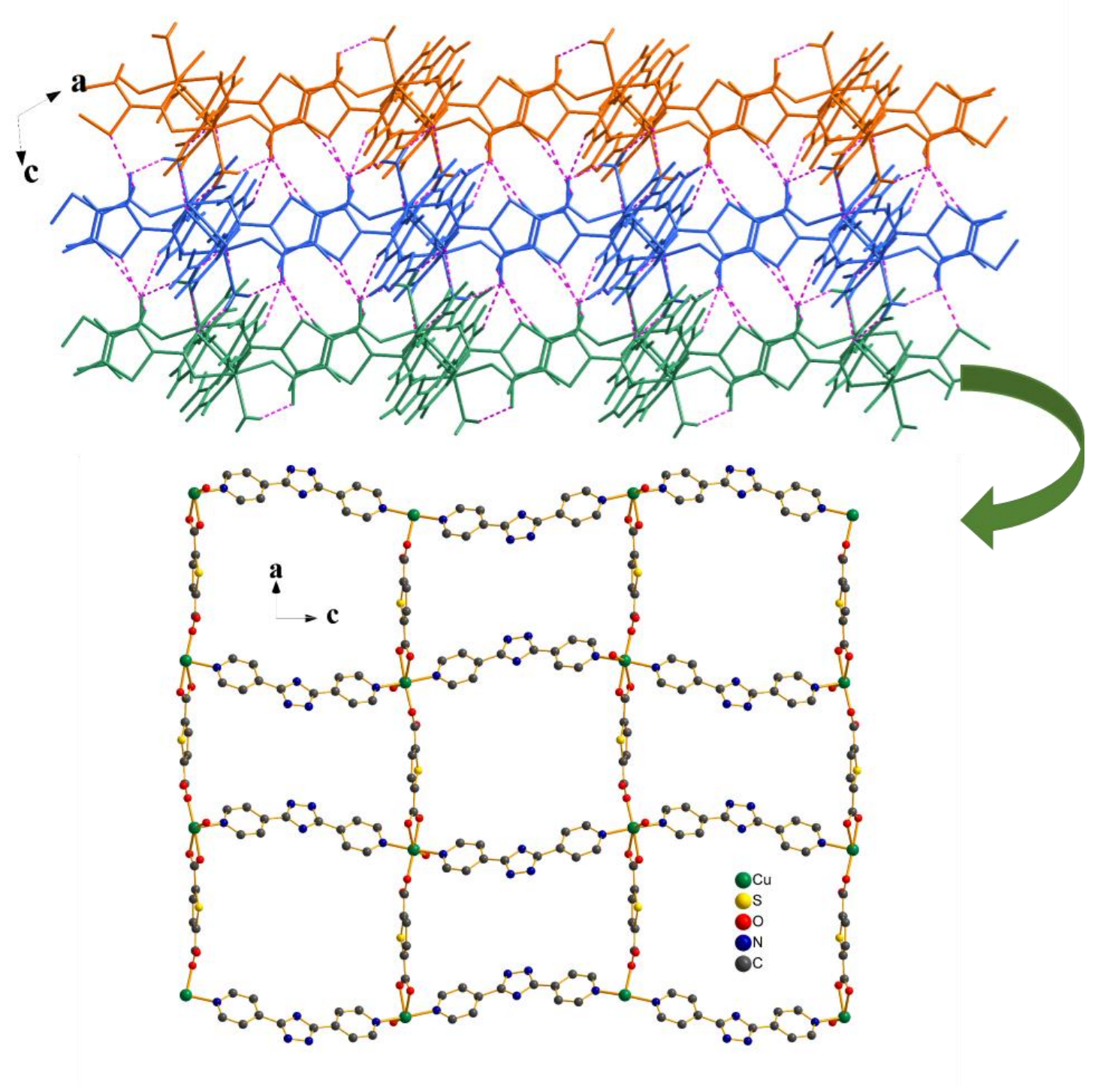

Fig. 3. 


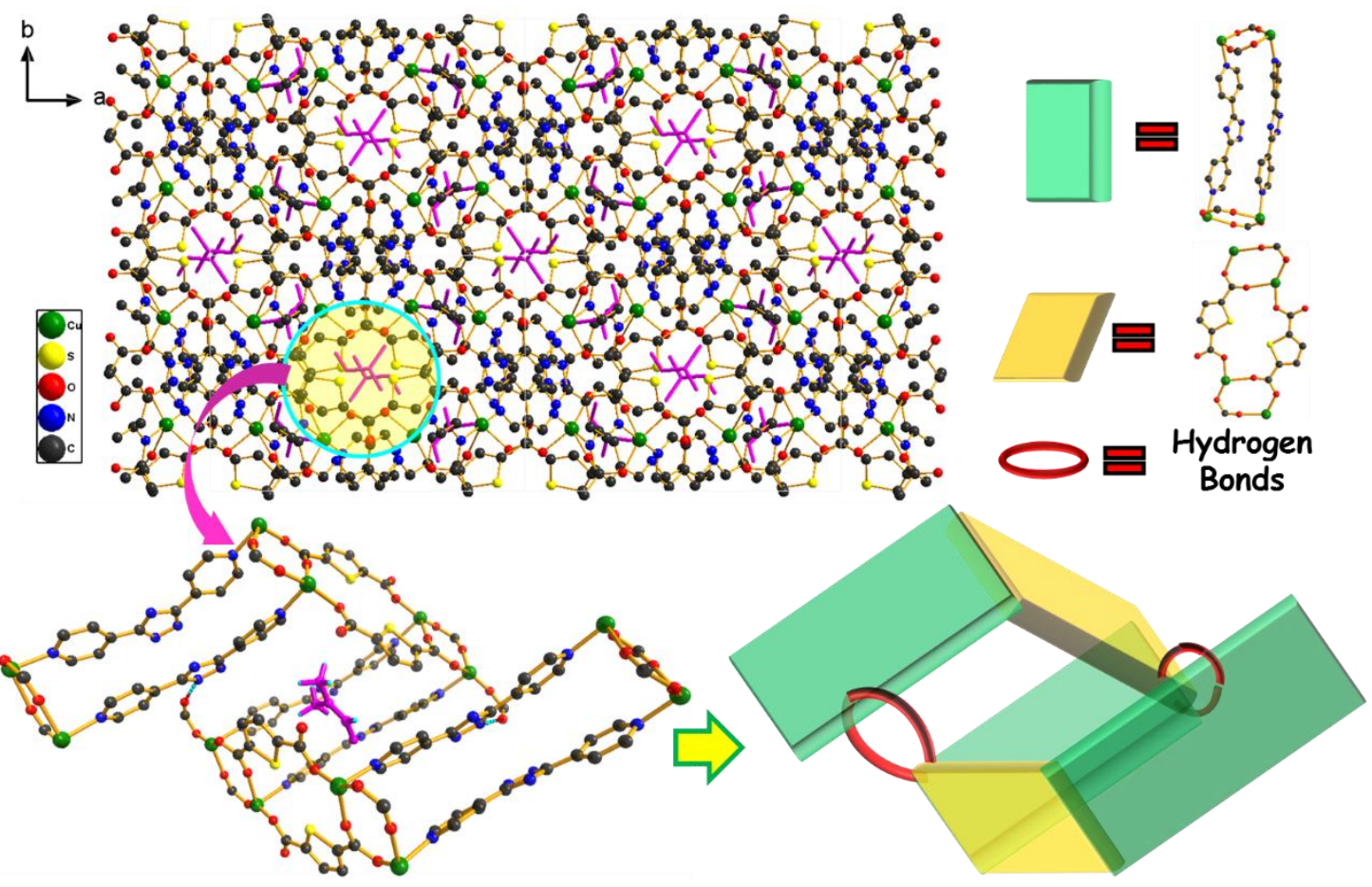

Fig. 4.

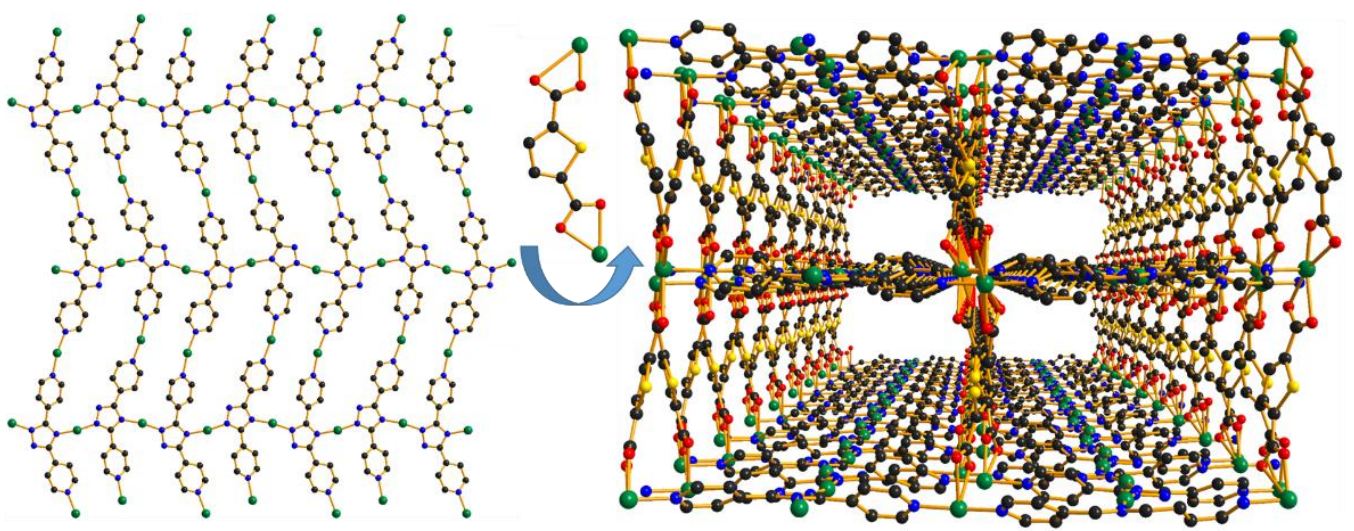

(a)

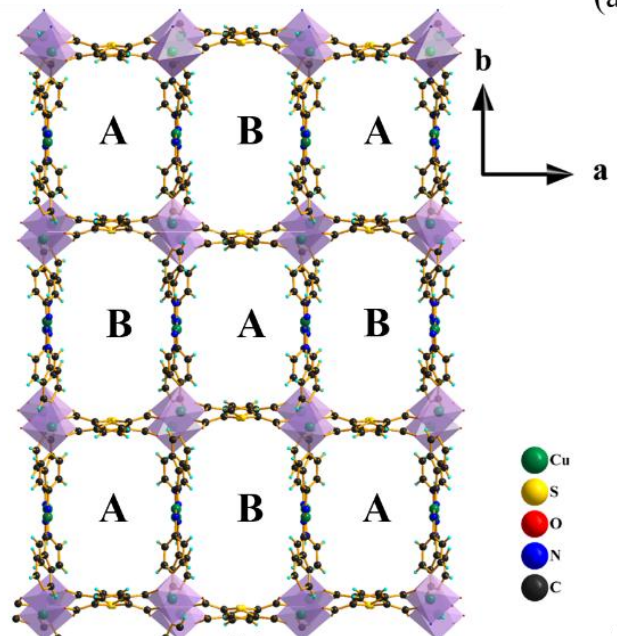

(b)

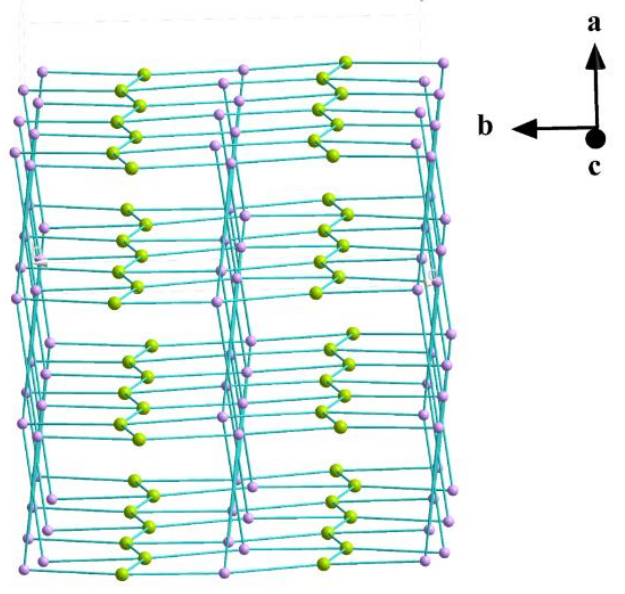

(c) 
Fig. 5.

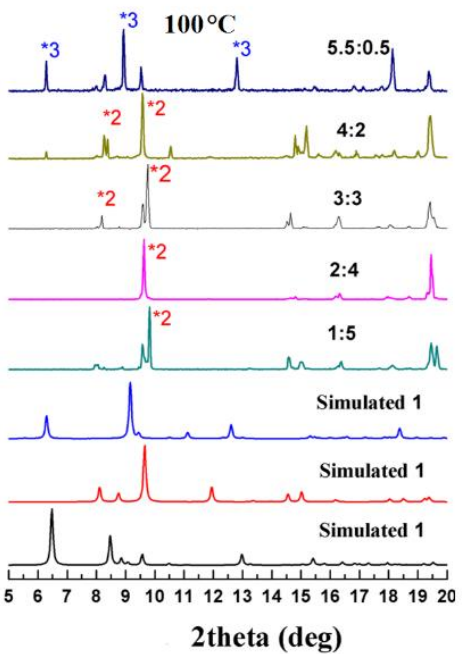

2theta (deg)

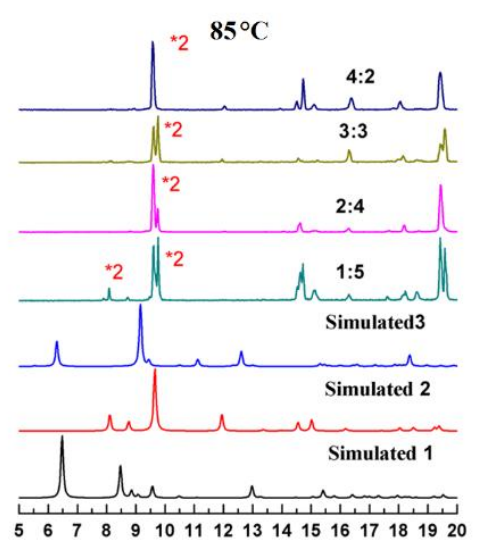

2theta (deg)
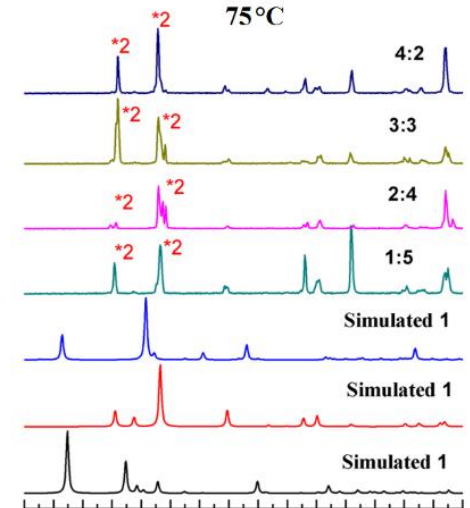

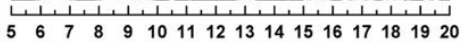
2theta (deg)
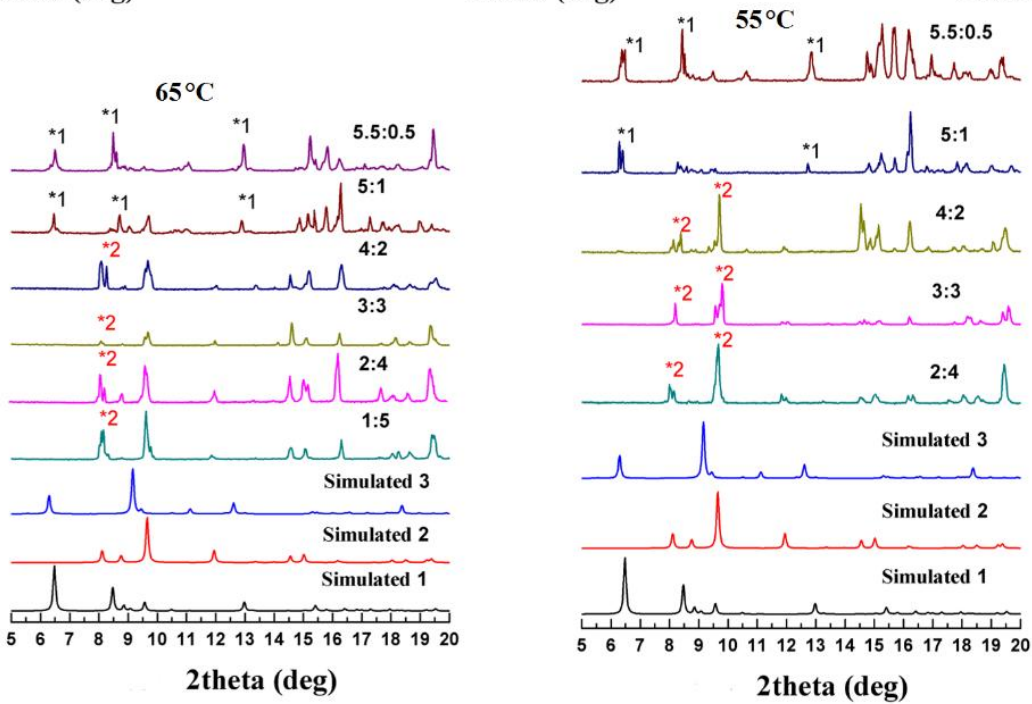

Fig. 6. 


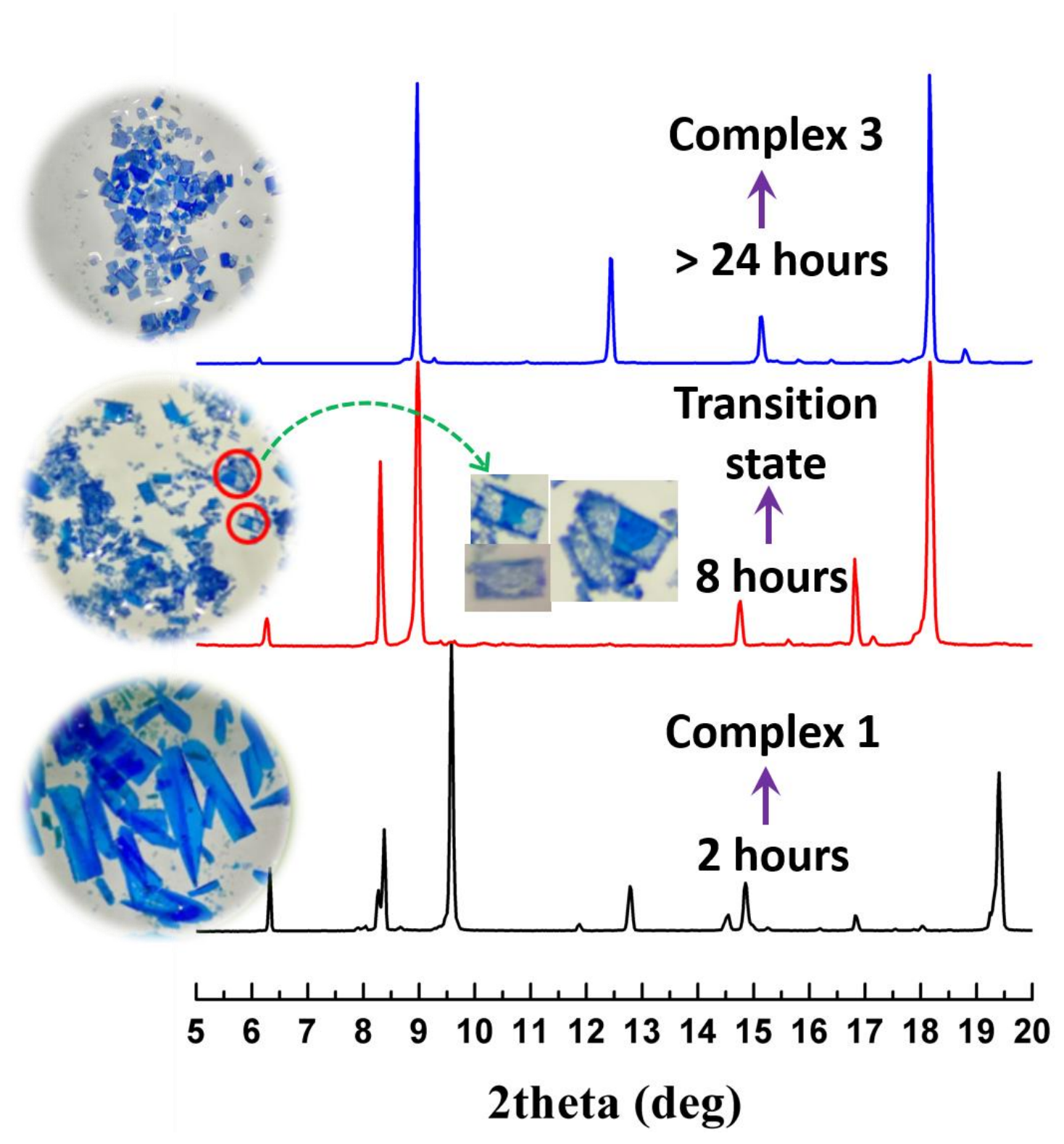

Fig. 7. 

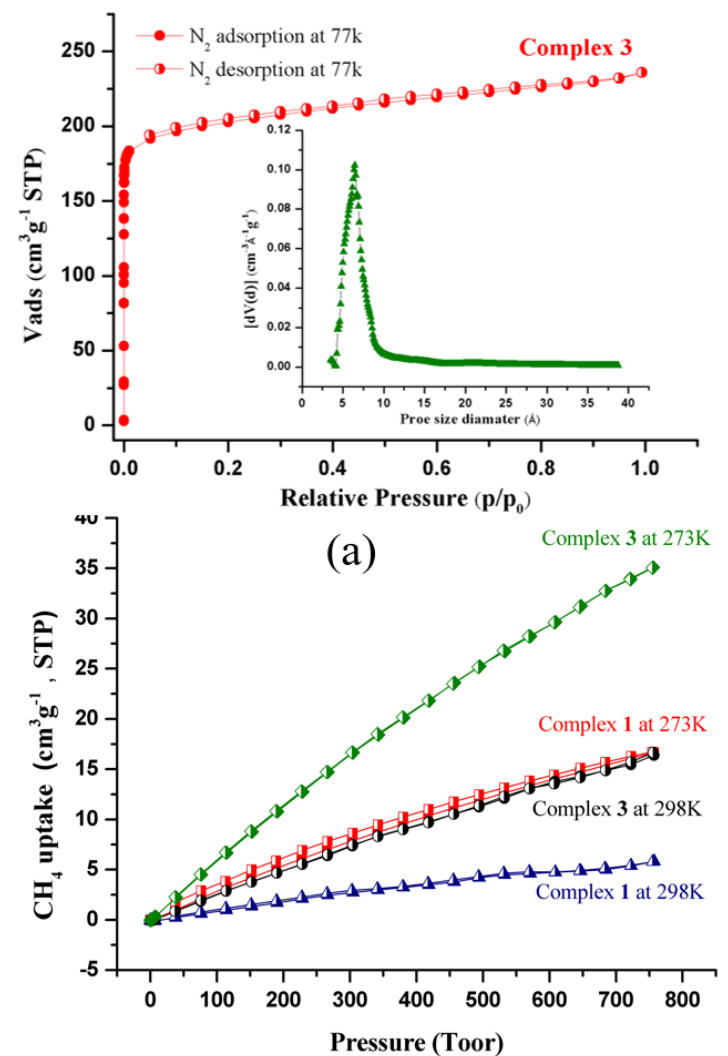

(c)
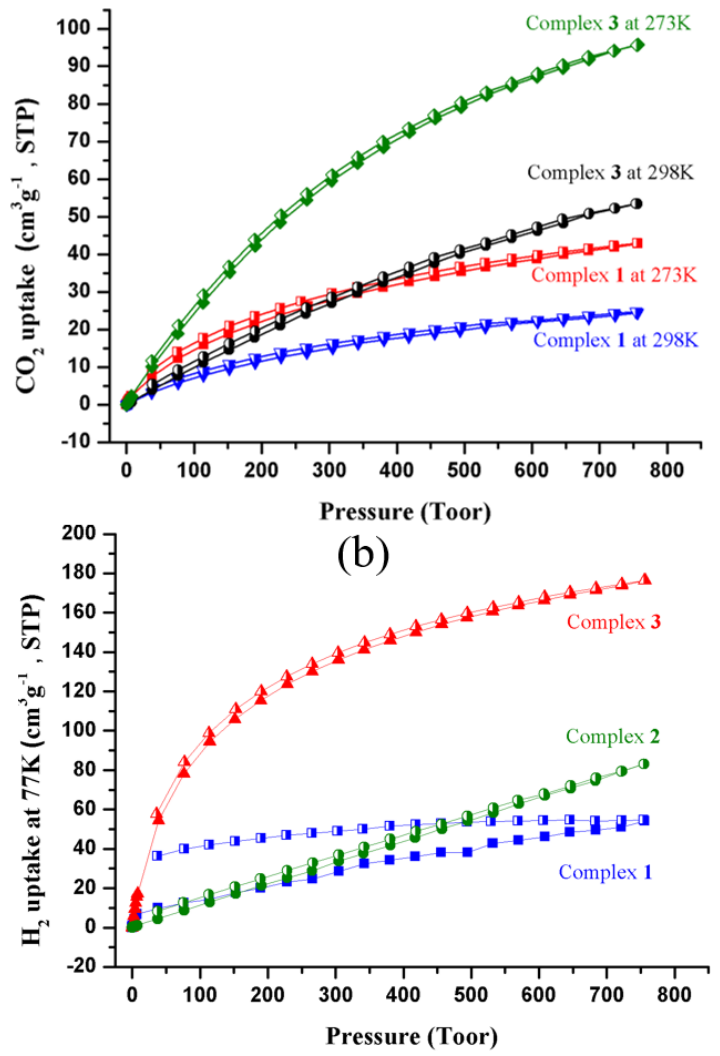

(d) 


\section{Graphical abstract}

\section{Controllable Assembly of Three Copper-Organic Frameworks: Structure Transformation and Gas Adsorption Properties}

Xiuling Zhang, Peng-fei Liu, Na Wang, Da-Shuai Zhang *

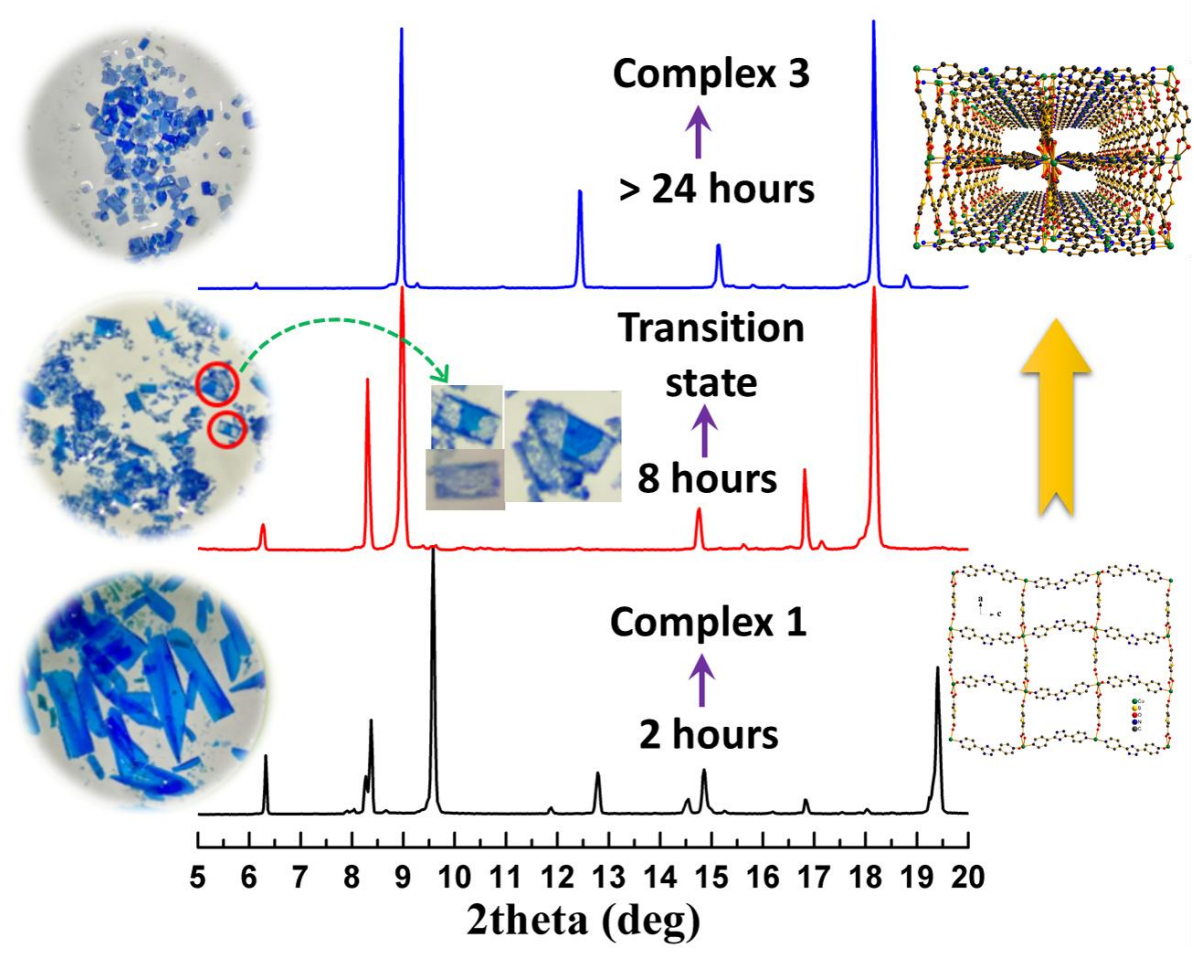

